\title{
Development and Validation of Academic Dishonesty Scale (ADS): Presenting a Multidimensional Scale
}

\author{
Hilal Bashir \\ Research Scholar, Department of Education, Lovely Professional University, Jalandhar, \\ Punjab, India, hilalbashir14@gmail.com
}

\section{Ranjan Bala}

Asst. Prof., Department of Education, Lovely Professional University, Jalandhar, Punjab, India, ranjan.16366@lpu.co.in

The purpose of the study was to develop a scale measuring academic dishonesty of undergraduate students. The sample of the study constitutes nine hundred undergraduate students selected via random sampling technique. After receiving expert's opinions for the face and content validity of the scale, the exploratory factor analysis (EFA) and confirmatory factor analysis (CFA) were applied. EFA favored a six factor structure viz: cheating in examination; plagiarism; outside help; prior cheating; falsification and lying about academic assignments. Moreover, the findings obtained from the CFA showed that the structure consisting of 23 items and the six factors associated to academic dishonesty scale (ADS) had adequate consistency indices. The internal consistency indices, alpha coefficient $(\alpha=.831)$ is adequate for the academic dishonesty scale (ADS). Results from the study confirmed multidimensionality and robust psychometric properties of academic dishonesty scale.

Keywords: scale development, factor analysis, academic dishonesty scale, students, undergraduate, academic dishonesty

\section{INTRODUCTION}

Academic dishonesty is a multifaceted and pervasive global phenomenon (Alleyne \& Phillips, 2011; Imran \& Nordin, 2013; Iberahim et al., 2013; McCabe \& Trevino, 1996; Nazir \& Aslam, 2010; Thomas, 2017; Tadesse \& Getachew, 2010; Saidin \& Isa, 2013; Whitley, 1998; Yang et al., 2013). The consequence of academic dishonesty has been long-lasting in many occurrences and its impediment for growth is largely alarming (Tadesse \& Getachew, 2010). In universities academic dishonesty occurs regularly and thus formulates a gigantic dilemma (Whitley, 1998) because at this juncture students are far from home and gain new ideas, new experience, and new peers in the novel milieu (Nonis \& Swift, 2010). In educational society ethical issues are eroding due to 
competition of today's job aspiration and the ideas of winning at any price and created scandals such as forging documents, trading credentials, deceiving and cheating. This menace could undermine the excellence of education as well as undermining the vision of grooming honest, accountable and trustworthy professionals in the future (Naghdipour \& Emeagwali, 2013). Moreover, several researches reported that students, who engaged in academic dishonesty, were more probably to engage in workplace dishonesty (Ellahi et al., 2013; Harding et al., 2004; Nazir \& Aslam, 2010; Nonis and Swift, 2001; Sims, 1993).

A penetrating examination of academic dishonesty suggests that a reliable and valid scale should be developed and the construct of academic dishonesty should be reexamined in every context what is labelled as dishonest behaviour in that academic scenario. The occurrence and degree of academic dishonesty has a number of educational implications for field experts as well as policy makers to reduce its intensity. In addition, the major concern is the validity of how academic dishonesty is assessed in institutional environment where academic dishonesty is prevalent. Educational researchers rely on standardized measures in classroom settings only to measure cognitive outcomes and no attention is paid in high frequency of cheating in teacheradministered exams (Grimes \& Rezek, 2005). Thus, it is essential for the investigators in the educational settings to understand that how academic dishonesty may affect on outcomes of human resources development. So, the sole purpose of this study was to bridge the gap and validate the scale which could possess sufficient psychometric properties specifying accuracy and consistency of measurement.

\section{CONTEXT \& REVIEW OF LITERATURE}

In previous studies of academic context, it is pertinent that numerous scales have been developed to examine academic dishonesty. Although, academic dishonesty is a phenomenon well-documented in the academic context (Lim and See, 2001), much is left undone about psychometric properties of most prior scales. As a result, conclusions/findings of those investigations are treated with cautions. However, as Imran and Nordin (2013) pointed out, most of the scales lacked proof of solid psychometric properties and their dimensionalities were not thoroughly investigated. This further contributes to high discrepancies in the conclusion for occurrence of academic dishonesty (Karlins et al. 1988; Nelson and Shaefer, 1986). What follows is a brief investigation of the present literature on scales and dimensionality of academic dishonesty in academia.

The literature suggests academic dishonesty is a multidimensional concept (Ferrari (2005); Iyer \& Eastman, 2006; 2008; Kaur, 2014; Roig \& DeTommaso, 1995). One of the most frequently used instrument is academic dishonesty scale with twelve statements, on a five point Likert format ranging on a 1 to (never) to five (many times) scale (McCabe and Trevino, 1993). This measure has been used in numerous studies as well as McCabe and Trevino (1997); Chapman et al. (2004); McCabe, Trevino and Butterfield (2001) or incorporated extra items (Brown, 1995; 1996; 2000; Bolin, 2004; Iyer \& Eastman, 2008; Kidwell et al., 2003). Despite its wider applicability in the academic dishonesty literature, the psychometric properties have not been critically 
investigated. Apart from a token of explanation on reliability coefficient, no further information on development and validation was provided (either through the exploratory and/or confirmatory factor analysis (Adesile, et al. 2016; Iyer and Eastman, 2006). Neither Brown (1996; 2000) nor Kidwell et al. (2003) reported any factor structure or reliability on the items (Iyer and Eastman (2006).

Notwithstanding its deficiency, researchers like Ferrari (2005); Roig and DeTommaso (1995) yielded that academic practices survey is a two dimensional construct viz: cheating (item associated to class tests and exams) and plagiarism (items associated to written homework). Moreover, Iyer and Eastman (2006) adapted the McCabe and Trevino's (1993) academic dishonesty scale. The adapted statements were said to be alike with those in Brown's $(1996 ; 2000)$ and Kidwell et al. (2003) investigations. Like in McCabe and Trevino (1993), a five-point scale ranging from 5 (= many times) to 1 (= never) was adapted. Even though it was asserted that Multitraits Multimethods (MTMM) investigation was used to ascertain discriminant and convergent validity of the measure, there was no solid proof concerning this examination.

The four components of academic dishonesty scale, according to Iyer and Eastman (2008) were plagiarism (made up of five statements), cheating (made up of five statements), electronic cheating (made up of two statements) and seeking outside help (made up of five statements) with alpha coefficients ranging from .70 to .85. Dawkins (2004) in their study yielded four components of academic dishonesty behaviour, although his investigation was a mere replica of statements highlighted to measure academic dishonesty by other studies. These dimensions included: copying from the internet; cheating on classroom tests; knowledge and awareness of others' (peers) cheating and lying to avoid detection. While Rawwas et al. (2004), in building on the research of Rawwas \& Isakson (2000), came up with four components for attitudes towards academic dishonesty namely receiving and abetting academic dishonesty (statements generally perceived as immoral and initiated by the student), ignoring prevalent practices (items that students may see as permissible and ethical) obtaining an unfair advantage (statements in which students take benefit of a condition not of their creation), fabricating information (statements that may not be clearly perceived as unethical). The reliability coefficients for each dimension were over .65 for a Chinese student sample and .70 for a United States student sample. Whereas Ledesma (2011) explored four components of self-reported measures of academic dishonesty namely cheating, outside help, plagiarism and tolerance. Elminoglu \& Nartgun (2009) developed academic dishonesty tendency scale based on four factors namely tendency towards cheating; dishonesty tendency at studies as homework/project etc; dishonesty tendency at research and process of write up and dishonesty tendency towards references.

Also, Hensley, Kirkpatrick \& Burgoon (2013) in a study on relation of gender, course enrolment and grades to distinct forms of academic dishonesty among undergraduate students in USA, used a 16-item scale adapted from Paulhus, Williams and Nathanson (2004). The 16-item measure entitled academic dishonesty scale yielded Cronbach's alpha 0.77 for cheating on tests, 0.77 for plagiarism and 0.70 for false excuses. 
However, like the other scales discussed, no additional information was given regarding the factor structure and validity of the scale's statements. Whereas Allen, Fuller \& Luckett (1998) developed perceived cheating index, included twelve specific forms of cheating. Many of the statements were alike in construct to that employed by McCabe \& Trevino (1993; 1997) and Brown (1995; 1996 \& 2000). Moreover, Munoz-Garcia \& Aviles-Herrera (2014) concurred with the four factors of academic dishonesty measure: falsification or deceptive conduct; group work; plagiarism and dishonest behaviour in academic work or examination. The range of the Cronbach's Alpha coefficient for these scales was $0.80-0.84$.

Notwithstanding these scales, Akbulut et al. (2008) yielded five components of internettriggered academic dishonesty scale viz: fraudulence, plagiarism, falsification, delinquency and unauthorized help. Whereas, Yang et al. (2013) adapted items from Akbulut et al's (2008) internet-triggered academic dishonesty scale, Rettinger and Kramer's (2009) list of academic violations and Yang's (2012) academic dishonesty scale and developed seven dimensional academic dishonesty scale by using factor analysis: plagiarism, cheating on an examination, deceptive infringement, improper cooperation, misuse of credit, concealment and tampering and behind-the-scenes work. In Indian context, Kaur (2014) developed academic cheating scale for adolescents. The scale comprised five dimensions i.e., cheating in examination, plagiarism, lying about academic assignments, interference during instructions \& damaging intellectual property. Furthermore, Jurdi, Hage \& Chow (2011) in a study on academic dishonesty in the Canadian classroom, developed a 17-item academic dishonesty measure, based on a five-point scale $(1=$ never to $5=$ more than 10 times). The behaviours pertained to cheating during examinations, plagiarism on written assignments, and falsification. In addition, Chukwuemeka et al. (2013) came up with two components of 16 items (scenario's) of academic dishonesty scale i.e. examination (item measuring cheating in examination) and coursework (items measuring cheating in coursework). Finally, Adesile et al. (2016) concurred with the three dimensions of academic integrity survey namely cheating, plagiarism and research misconduct.

The above notwithstanding, a situation was made for measuring academic dishonesty under a specific form rather than using general statements. The significance of asking statements about specific occurrences of academic dishonesty, as contrasting to common ones, is documented by Chapman et al. (2004). Swift and Nonis (1998) found that, when participants were asked about academic dishonesty in common terms, sixty percent of the participants admitted to having cheated at least once, but when the summated score for all specific forms of cheating behaviour are summated, eighty seven percent of the participants admitted to having cheated at least once. Thus, identifying specific dishonest behaviours may expose dishonesty better than common statements (Nonis \& Swift, 1998).

At present, investigators have developed number of academic dishonesty measures but in Indian context no such scale has been constructed; this study will fill up the gap and present a multidimensional construct in Indian scenario. With this measure researchers will come to know the level of engagement of undergraduate students in academic 
dishonesty because dishonest behaviour has severe negative consequences for institutions and students. The academic dishonesty violates scientific principles, as well as study and assessment regulations. Moreover, constant evaluation and validation of scales is a key to assurance that psychological/behavioural construct(s) are defined and measured properly (Hair et al. 2010). For this explanation, Hair et al. strongly suggested that investigators should always verify the unidimensionality and validity of their constructs even if well-established instruments are involved. We designed a study to explicitly explore the dishonest behaviours among undergraduate students. The present investigation seeks to uncover the academic dishonesty research, address the lack of thorough examination of moral issues in educational endeavours in India and validate academic dishonesty scale for undergraduate students.

\section{METHOD}

Keeping in mind the objectives, scale development study was used to develop an instrument that sufficiently measures the academic dishonesty of undergraduate students. The procedures were as follows (i) definition of the construct intended to be measured (ii) generation of an item pool (iii) expert views on initial item pool (iv) refinement and validation of the scale (v) evaluation of the scale (DeVellis, 2016; Netemeyer et al. 2003; Worthington \& Whittaker, 2006; Wymer \& Alves, 2012). In addition, details related to participants, instrument and procedures and data analysis can be seen in detail below.

\section{Participants}

The population of the study is undergraduate university students of Jammu and Kashmir (India). The participants in this research were 900 undergraduate university students in Kashmir province of Jammu and Kashmir, who were selected via simple random sampling technique. This technique has been selected for some benefits; including ease of use, accuracy of representation and exhibit low sampling error (Singh, 2008). There are $51.11 \%$ male and $48.89 \%$ female undergraduate students. Initially, out of three provinces of Jammu and Kashmir, one province was selected randomly i.e., Kashmir. In this province, six colleges were selected randomly. From those colleges, several students were picked up conveniently as participants. The researcher collects information from all the participants that are conveniently available, and willing to co-operate for providing information (Kaul, 2009). The sample size was adequate for acceptable threshold of EFA and CFA separately as recommended by (Heir et al. 2010).

\section{Instrument and Procedures}

In this investigation rigorous literature was studied in order to develop a reliable scale. In initial stage, Item generation was based on our theoretical model; we developed statements related to academic dishonesty in Indian scenario. The generated statements were intended to capture academic dishonesty of undergraduate students. In initial stage, 52 statements were generated by the investigators. The extensive review of literature guides us to produce an instrument with robust psychometric properties and clear dimensionality for academic dishonesty among undergraduate students. Therefore, summated evaluation method proposed by Likert (1932) has been used for developing 
present scale. Likert scaling is commonly used tool measuring beliefs, options and attitudes. It is frequently helpful for these items to be literally strong when used in a Likert format (DeVellis, 2016). Therefore the present scale comprised 5-point Likert format, each statement is rated on five sequential points, (always $=5$, frequently $=4$, sometimes $=3$, rarely $=2$ and never $=1$.

After preparing the item pool, the face and content validity was qualitatively performed with the involvement of sixteen experts who hold doctorates in the field of education and psychology with a request to suggest any ambiguity, vagueness or dual meaning coming from any statement. An expert judgement is a general procedure of item construction (DeVellis, 2016; Netemeyer, Bearden, \& Sharma, 2003). Analysis and revisions were performed based on advice from experts. The experts were of the opinion that the statements of scale are completely satisfactory and relevant to measure the academic dishonesty of undergraduate students in Indian context. Only those statements were retained in primary draft which had complete agreement among experts with regard to relevance of items.

In order to analyse the expert viewpoints, an evaluation tool consisting of three items was used. In this assessment tool, the experts were asked to choose one of the options "Retain or Suitable", "Modify or Must be corrected" and "Delete or Not suitable". By combining all the evaluation tools as one evaluation tool, the issue of how many experts approved each possible option of the items was determined. In this perspective, the content validity of the statements was determined with the "(The number of the experts who answered positively/The number of total experts)-1" formula for each item (Veneziano \& Hooper, 1997). After this calculation, the items having content validity ratios (CVR) below 0.80 were excluded from the scale. Due to this 14 statements were deleted and further 38 items were retained to perform the exploratory factor analysis. The total score of all the statements obtained by examinee is considered as total academic dishonesty. High score on the measure denotes a higher level of involvement of undergraduate students in academic dishonesty.

\section{Data analysis}

In order to test the reliability and validity of the academic dishonesty scale, it was preapplied to 450 undergraduate students, who were sample of the study. The Kaiser-Meyer Olkin (KMO) coefficient was applied to determine whether the sampling size was appropriate for factorization or not, and the Barlett Test of Sphericity was applied to determine whether or not the data were from multivariate normal distribution. The validity assessment of the scale was performed by examining the structural validity. For the structural validity, the factorial structure of the scale was determined by using the Explanatory Factor Analysis (EFA) and Confirmatory Factor Analyses (CFA). The Explanatory Factor Analyses is applied to determine the association between the unknown latent variables and the observed variables (Schreiber et al. 2006). This analysis is defined as being explanatory or a discoverer for researchers who do not have any idea on the issue of under which factor the items perform measurements in reality (Byrne, 1994). As a matter of fact, it is expected in factor analysis, which is performed to locate the variable in the factor group in question, that the factor loads are high. When 
the literature is scanned it is observed that there is a widely-held belief that an item must have at least 0.30 minimum size for the factor load of the relevant item. According to Tabachnick and Fidell (2001), the load value of each variable must be evaluated at or over 0.32 as a basic rule.

The CFA, on the other hand, is beneficial in efforts to develop, organize and review the measurement scales (Floyd \& Widaman, 1995). According to Kline (2005), in the CFA results of a measurement model, the correlation predictions among the factors, the loads under the factors to which the indicators are connected, and the amount of the measurement error for each indicator are given. CFA is the most influential analysis used to assess whether a pre-defined factor model fits the data (Floyd \& Widaman, 1995; Netemeyer et al. 2003). Many fit indices are used in order to determine the adequacy of the model tested in CFA (Joreskog \& Sorbom, 1993). In this study, the ChiSquare Goodness Test, Goodness of Fit Index (GFI), Adjusted Goodness of Fit Index (AGFI), Comparative Fit Index (CFI), and Root Mean Square Error of Approximation (RMSEA) were examined for CFA. In these goodness indices, GFI, AGFI and CFI, being >.90, RMSEA being <.08 are considered as criteria, which is generally the situation (Kline, 2005; Tabachnick \& Fidell, 2001). The internal consistency (alpha) coefficients were examined for the reliability investigation of the academic dishonesty scale. The SPSS 22.0 and AMOS 24.0 programs were used for the validity and reliability analysis of the scale.

\section{FINDINGS}

In this section, the findings on reliability and validity tests, which were conducted to develop the academic dishonesty scale are provided.

\section{Exploratory Factor analysis}

Factor analysis is one of the most commonly used procedures in the development and validation of psychological constructs (Floyd \& Widaman, 1995). Kaiser-Meyer-Olkin (KMO) and Barlett Sphericity tests were applied to determine whether the 38-item scale fit the factor analysis or not. Several iterative cycles of factor analysis were conducted on the data set. The total variance explained and numbers of factors extracted were examined after each iteration. Factors with low communalities and which didn't correlate were deleted with the aim of improving the factor structure to get a matrix with much clear loadings. The Kaiser-Meyer-Olkin (KMO) value, which is used to determine whether the data and the sampling size are adequate and suitable for the selected analysis, was found to be .849 . In addition, the Barlett Sphericity test, which is used to check whether the data come from multi-variate normal distribution or not, was applied and the result was found to be significant (Chi-square=2610.357, $p<.01$ ). It is necessary that the KMO measurement test result is .60 and over, and the result of the Barlett Sphericity test is statistically significant (the minimum acceptable coefficient is .60 (Tabachnick and Fidell, 1996). Since the values obtained as a result of the above mentioned analysis fit the basic hypotheses at a good level, it was decided that the factor analysis could be conducted (Kothari \& Garg, 2014). 
Table 1

KMO and Bartlett's Test of Sphericity

\begin{tabular}{lll}
\multicolumn{2}{l}{ Kaiser-Meyer-Olkin Measure of Sampling Adequacy. } & .849 \\
Bartlett's Test of Sphericity & Approx. Chi-Square & 2610.357 \\
& Df & 253 \\
& Sig. & .000 \\
\hline
\end{tabular}

Since the factor loads show the correlation between the item to be measured and the main structure, the relevant dimensions that appeared as a result of the basic component analysis and the factor loads were examined. After these processes, the last form of the academic dishonesty was given as 23 items. The rotated components matrix, which was converted with Varimax method, and which was obtained as a result of the exploratory factor analysis, is given in table 2. The Varimax method, which is one of the vertical rotating methods, was preferred in order to ensure that the factor variances would have high value with a few variables. The factor analysis revealed a six factor structure, explaining $55.67 \%$ of the variance (Streiner, 1994) and all items loading above .40 (Acceptable item loading of above sample 350 is 0.40 (Heir et al. 2010). The first factor consisted of items associated to cheating in examination (5 items), second factor consisted of items associated to plagiarism (4 items), third factor associated to outside help (4 items), fourth factor associated to prior cheating (3 items), the fifth factor associated to falsification ( 3 items), and six factor associated to lying about academic assignment (4 items). The Table 2 indicates items and their factor loadings of academic dishonesty scale.

Table 2

Items of Academic Dishonesty Scale (ADS) and their Factor Loadings

\begin{tabular}{|c|c|c|}
\hline S. No & Items & Factor loadings \\
\hline Factor: One & Cheating in Examination (CE) & \\
\hline Item7 & During examination I use signals to fetch answers from my friends. & .439 \\
\hline Item8 & $\begin{array}{l}\text { I use prohibited things like hidden notes, calculators and other electronic } \\
\text { devices during examination. }\end{array}$ & .759 \\
\hline Item9 & $\begin{array}{l}\text { I interchange my allotted book with other student to get better grade in } \\
\text { examination. }\end{array}$ & .753 \\
\hline Item 10 & $\begin{array}{l}\text { During an examination, I solve answers on question paper and handover to } \\
\text { my classmates. }\end{array}$ & .697 \\
\hline Item14 & During a test I try to copy from another student. & .472 \\
\hline Factor: Two & Plagiarism (PL) & \\
\hline Item 22 & $\begin{array}{l}\text { I copy summary of a story/poem/chapter from a textbook \& claim it as } \\
\text { completed by me. }\end{array}$ & 615 \\
\hline Item26 & $\begin{array}{l}\text { For submitting assignment, I copy and change few sentences/lines/words and } \\
\text { phrases from other sources. }\end{array}$ & .780 \\
\hline Item 27 & $\begin{array}{l}\text { I use online resources in my personal educational assignment/project without } \\
\text { citing the author. }\end{array}$ & .743 \\
\hline Item 25 & $\begin{array}{l}\text { For personal comments I manipulate scientific information on internet and } \\
\text { claim it as written by me. }\end{array}$ & .463 \\
\hline Factor: Three & Outside Help $(\mathrm{OH})$ & \\
\hline Item17 & $\begin{array}{l}\text { I attempt to make special considerations to attain or getting favours i.e. } \\
\text { (bribery) }\end{array}$ & .689 \\
\hline Item19 & In an individual work/assignment I take help from others to complete it. & .571 \\
\hline Item 20 & $\begin{array}{l}\text { I use unfair means to obtain information about the content of the test before it } \\
\text { was given. }\end{array}$ & .413 \\
\hline
\end{tabular}




\begin{tabular}{|c|c|c|}
\hline Item18 & Before examination I try to know questions asked in paper. & .640 \\
\hline Factor: Four & Prior Cheating $(\mathrm{PC})$ & \\
\hline Item28 & I write expected answers on table/wall/hand/paper etc. in prior time. & .682 \\
\hline Item29 & $\begin{array}{l}\text { I interchange my allotted seat near efficient student to get better grade in } \\
\text { examination. }\end{array}$ & .731 \\
\hline Item33 & Before examination I encourage other classmates to do cheating. & .564 \\
\hline Factor: Five & Falsification & \\
\hline Item2 & I submit the assignment in my name after getting it prepared by my friends. & .605 \\
\hline Item3 & I damage library books so that classmates do not get required content. & 689 \\
\hline Item6 & In a course I submit the same educational assignment more than one time. & .447 \\
\hline Factor: Six & Lying about Academic Assignments & \\
\hline Item15 & I give false explanations when I miss deadline of my educational project. & .534 \\
\hline Item37 & I buy a project/assignment/paper online \& submit it as my individual effort. & 649 \\
\hline Item32 & Before exam I pay someone to write a paper/homework for me. & .477 \\
\hline Item38 & I provide false excuses to teacher, to gain extra time on project/assignment. & .624 \\
\hline
\end{tabular}

\section{Confirmatory factor analysis}

According to Joreskog \& Sorbom (2004) confirmatory factor analysis is a distinct case of Structural Equation Modelling which is also known as linear structural relationship model. Even though exploratory factor analysis gives an idea of dimensionality, confirmatory factor analysis, as the name implies, basically focuses on whether a hypothesized factor model does or does not fit the data set. Thus, confirmatory factor analysis is now a universally accepted technique to confirm dimensionality (Floyd \& Widaman, 1995; Netemeyer et al. 2003). The confirmatory factor analysis was applied using IBM-SPSS Amos 22 version to six factors extracted in exploratory factor analysis. The structure of the academic dishonesty scale, which consisted of 23 items and six factors, was tested by using the confirmatory factor analysis. This analysis was made over 450 students, who were selected conveniently. The findings obtained as a result of analyzing the model with confirmatory factor analysis are given below.

The final indices of the model were (CMIN/DF=2.173, Goodness Fit Index (GFI) =.915, Adjusted Goodness of Fit Index (AGFI) $=.901$, Comparative Fit Index (CFI) $=.870$, Root Mean Square of Approximation (RMSEA) $=.051$ and Chi-square $=464.93$ $(p>0.01)$. The standard values for the indices: The GFI, CFI and AGFI values must be between 0 and 1 . Although there is no agreement on these values in the literature, if the values are over 0.90, this is the evidence of a good fit (Schumacker \& Lomax, 2016). However, (Hair et al. 2010) suggested that CFI value >.85 is acceptable but CFI $>.90$ is considered better fit (p. 647). In addition several studies such as Gay et al. (2010); Mahne \& Huxhold (2014); Lima-Rodríguez et al. (2015), have CFI value which is lower than .90 . The RMSEA values also vary between 0 and 1 . The more these values are close to 0 , the more they indicate a fit. So, RMSEA is a good fit indicator in this model (Hooper, 2008; Hu and Bentler, 1999; Jpreskog \& Sorbom, 1993; Kline, 2005). Nonetheless researcher like Schumacker \& Lomax (2016) suggested that if majority of the fit indices are over threshold value, then it can be concluded that theoretical model is supposed by the data. As a result, all the standard fit indices show that the factor structure of the model is approved. Figure 1 provides a holistic view of the confirmatory factor analysis model. 


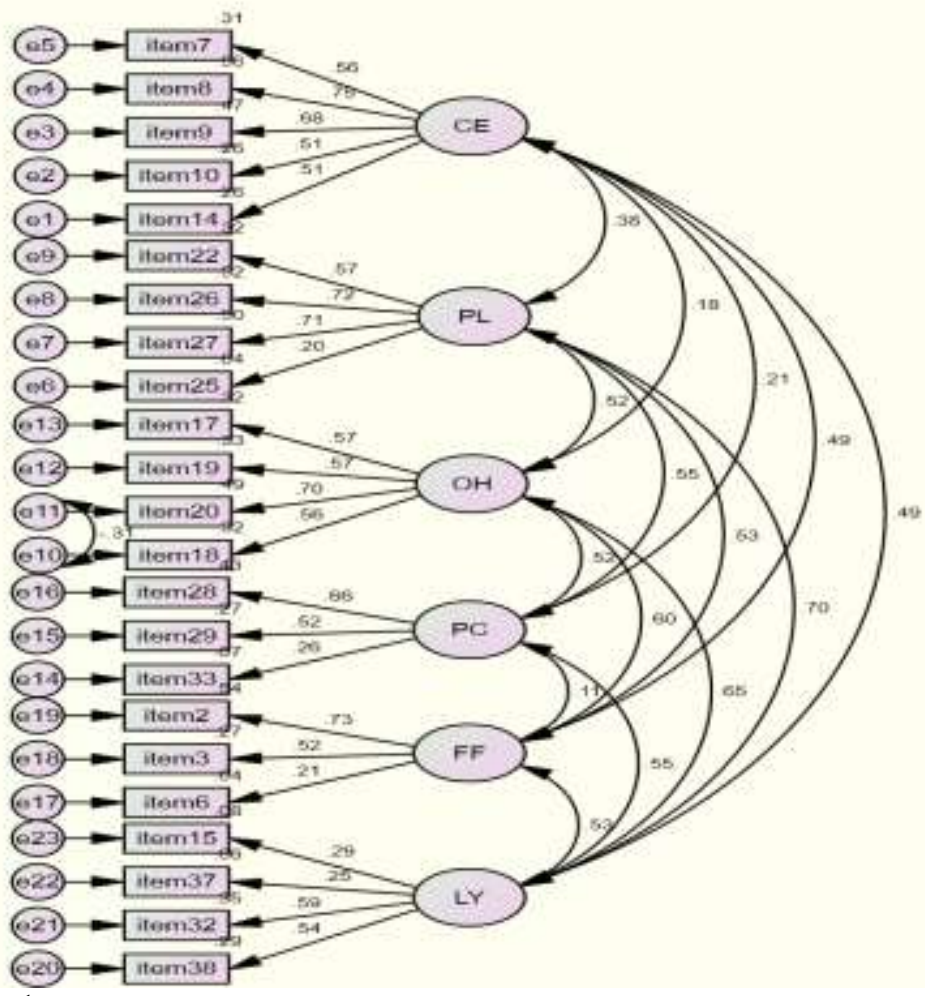

Figure 1

Confirmatory Factor Analysis Model of Academic Dishonesty Scale

\section{Reliability Analysis}

The alpha coefficient is regularly used to measure the internal consistency. In practice, it is essential to verify whether the alpha $(\alpha)$ coefficient is high (Hayashi \& Kamata, 2005). So, the reliability was measured by interpreting the obtained value of Cronbach's Alpha (Cronbach, 1951) to assess the internal consistency of the scale. The internal consistency of each factor is greater than the recommended coefficient of 0.6 (Hair, et al. 2010). Also, the internal consistency score for each of the scales ranged from moderate to high, with the least Cronbach's alpha reliability reaching 0.621-0.731. In addition, several studies such as Adnanes (2007); Jurdi, et al. (2011); Rawwas \& Isakson (2000), have Cronbach's Alpha value which is lower than .70. Furthermore, Cronbach's Alpha for overall scale was found to be .831 which is also shown in Table 3. This illustrates a high degree of internal consistency among the items. The interpretation made by Gliem \& Gilem (2003) shows that the reliability coefficient Alpha normally ranges from 0 and 1 . But, there is no lower limit to alpha coefficient and closer the value of alpha to 1.0, greater is the internal consistency of the measure (p.87). The thumb rule acknowledged by George \& Mallery (2003) for the interpretation of Alpha is: " 0.80 to 
0.9 Good; and above 0.9 Excellent". For this scale Cronbach's alpha indicated good internal reliability $(\alpha=.831)$. So, our reliability analysis suggests that academic dishonesty scale is internally consistent.

Table 3

Reliability Statistics of Academic Dishonesty Scale

\begin{tabular}{ll}
\hline Cronbach's Alpha & Number of Statements \\
\hline .831 & 23 \\
\hline
\end{tabular}

\section{Intercorrelations of the Academic Dishonesty Scale}

Pearson's coefficient of correlation demonstrated higher levels of significant positive correlations of all dimensions of academic dishonesty (Cheating in examination, Plagiarism, Outside help, Prior cheating, Falsification and lying about academic assignments respectively) with overall ADS. As the table indicates, the model with best fit demonstrated inter-correlation between factors and academic dishonesty scale ranges from .528 to .728 which is also shown in table 4 .

Table 4

Intercorrelations for cheating in examination, Plagiarism, Outside help, Prior cheating, Falsification, Lying about academic dishonesty and total academic dishonesty scores

\begin{tabular}{llllllll}
\hline Measure & CE & PL & OH & PC & FF & LY & TAD \\
\hline CE & 1 & $.316^{* *}$ & $.175^{* *}$ & $.195^{* *}$ & $.338^{* *}$ & $.440^{* *}$ & $.672^{* *}$ \\
PL & & 1 & $.378^{* *}$ & $.304^{* *}$ & $.354^{* *}$ & $.441^{* *}$ & $.711^{* *}$ \\
OH & & & 1 & $.350^{* *}$ & $.427^{* *}$ & $.345^{* *}$ & $.672^{* *}$ \\
PC & & & & 1 & $.125^{* *}$ & $.280^{* *}$ & $.528^{* *}$ \\
FF & & & & & 1 & $.280^{* *}$ & $.613^{* *}$ \\
Ly & & & & & 1 & $.728^{* *}$ \\
\hline
\end{tabular}

**Significant at 0.01level

Note: $\mathrm{CE}=$ Cheating in Examination; $\mathrm{PL}=\mathrm{Plagiarism}$; $\mathrm{OH}=\mathrm{Outside} \mathrm{Help} ; \mathrm{PC}=$ Prior Cheating; FF=Falsification; LY=Lying about Academic Assignments; TAD $=$ Total Academic Dishonesty

\section{Construct validity of Academic Dishonesty Scale}

The construct reliability (CR) of academic dishonesty scale is adequate as per the researcher i.e. 70 (Hair et al. 2010). A sufficient criterion is obtained for construct reliability (CR) with the cheating in examination factor of 0.829 , plagiarism 0.779 , outside help 0.797, prior cheating 0.730 , falsification 0.714 and the lying about academic assignments of 0.781 . Based on these six criteria, each factor has adequate convergent validity while the AVE value $<0.5$. In the current research study, the discriminant validity was assessed by using the pattern method of (Fornell and Larcker, 1981), which states that, "discriminant validity exists when Squared Inter construct correlation (SIC) is less than average variance extracted (AVE)". For this purpose, square inter constructs correlation (SIC) is less than the AVE which indicates good discriminant validity. Hence, the constructs are truly distinct from others. Therefore, these aspects reflect the construct validity of the scale. On the other hand, the factor loadings, reliability measures also provide strong evidence for the construct validity. 


\section{DISCUSSION AND CONCLUSION}

In this investigation, the aim was to develop a scale that would allow obtaining valid and reliable results in academic dishonesty of the students. The study has scanned a broad literature of the existing state of academic dishonesty in academic context. A painstaking methodological procedure was carried out to develop and validate measurement of academic dishonesty based on qualitative assessment. In the light of the expert viewpoints, the entire group of 52 statements was submitted with a request to suggest any ambiguity, vagueness or dual meaning coming from any statement. In addition, expert opinions were received in order to ensure the content and face validity of the scale. 14 items were excluded from the item pool that was initially formed. In this way, a draft form consisting of 38 items were obtained with the 5-point Likert format ranging on a 5 to (always) to 1 (never) scale. The structural validity of the scale was analyzed with EFA and CFA. Twenty three items were retained from the scale after EFA and a structure consisting of six factors were obtained. The factor loading values of the items varied between .413 to .780 and explained $55.67 \%$ of the total variance.

The exploratory factor analysis revealed that academic dishonesty can be decomposed or conceptualized into 6 factors consisting of Cheating in examination (05 statements), Plagiarism (04 statements), Outside help (04 statements), Prior cheating (03 statements), Falsification (03 statements) and lying about academic assignments (04 statements) respectively. Similarly confirmatory factor analysis was performed to confirm the factor structure of academic dishonesty scale. The factors that were obtained at EFA were tested with CFA. The indices of the model were (CMIN/DF=2.173, Goodness Fit Index $(\mathrm{GFI})=.915$, Adjusted Goodness Fit Index (AGFI) =.901, Comparative Fit Index (CFI) $=.870$, Root Mean Square of Approximation $($ RMSEA) $=.051$ and Chi-square $=464.93$ ( $p>0.01)$ values have acceptable good fit values. When the fact that the fit indices computed in CFA are in acceptable limits is considered, it is possible to claim that the structural validity of the measurements obtained from academic dishonesty has been achieved. Moreover, reliability coefficient was calculated which exhibits high degree of internal consistency $(\alpha=.831)$ which is good as acknowledged by George $\&$ Mallery (2003). The scale passed all criteria like structural validity, reliability and construct validity.

For instance, the scale not only has adequate statistical buttress but also has ample theoretical support. The factors which are extracted through exploratory factor analysis and validated through confirmatory factor analysis also have similar references in empirical studies. The factor/domain cheating in examination was used in prior studies (Eminoglu \& Nartgun, 2008; Ferrari, 2005; Iyer and Eastman, 2008; Kaur, 2014; Roig \& Detommaso, 1995; Rawwas and Isakon, 2000; Yang et al., 2013). Similarly, Plagiarism was used by numerous researchers like (Akbutal et al., 2008; Ferrari, 2005; Iyer and Eastman, 2008; Kaur, 2014; Roig \& Detommaso, 1995; Unal, 2011). For Outside help (Iyer and Eastman, 2008; Ledesma, 2011), Prior cheating (Ellahi et al., 2013), which refers to tendency of dishonest academic acts existing before actual time of commencement of examination such as writing expected answers on table/hand/wall etc or interchange allotted seat to get better grades. Falsification (Akbutal et al., 2008; 
Jurdi et al., 2011; Munoz-Garcia \& Aviles-Herrera, 2014; Rawwas \& Isakon, 2000). Last factor lying about Academic assignments was used by (Kaur, 2014). Finally, the evidence of this study suggests that this scale has robust psychometric properties to measure dishonest behavior of undergraduate students. As a result, it was concluded that the scale, which was developed in the scope of the study, is a scale that produces valid and reliable results, and may be used in determining the academic dishonesty of undergraduate students. Inspite of this, academic dishonesty affects human resource development because students who exhibit dishonest behavior, do not learn, which opposes the mission of higher education since performance of dishonest academic acts devalue the quality of a college degree (Keith-Spiegel \& Whitley, 2001).

In this Investigation, researcher has used highly valid and reliable scale development procedures but still it suffers from some limitations. The first limitation is that both the techniques of the scale refinement like the exploratory factor analysis and the confirmatory factor analysis are quite sample size specific. Investigators in this study have a rationale and proper literature support for applying these techniques but in order to have better results a bigger sample size is advisable. The main challenge related with developing a new scale such as the academic dishonesty (AD) is the complexity linked with obtaining scores that are valid and reliable. The findings provide support for conducting further psychometric examination on the academic dishonesty scale (ADS). However, in this study CFI value is near about the threshold value so further investigation should be conducted to improve the fit indices of academic dishonesty scale. Statements should be revised, added, modified or deleted to improve consistency/reliability of the measures of subscales of academic dishonesty to make ensure that a similar number of statements are assessing each of the components. Moreover, test-retest data should also be obtained to establish the stability of the academic dishonesty over time.

In addition, a triangulation approach can be used to assess the causes and consequences of academic dishonesty in academic institutions. While as multi-campus investigation should be conducted to assess the perception of teachers as well as students towards academic dishonesty. In particular, administering the measure to undergraduate students at universities might lead program developers, curriculum framers, educationalists, administrators and policy-makers to determine most epidemic factors of dishonest behaviour and take indispensable measures consequently. This study suggests that follow up investigation with this instrument across various campuses to get an image of undergraduate students in India in requisites of the intensity of unethical behaviour.

\section{REFERENCES}

Adesile, I., Nordin, M. S., Kazmi. Y., \& Hussien, S. (2016). Validating Academic Integrity Survey (AIS): An Application of Exploratory and Confirmatory Factor Analytic Procedures. Journal of Academic Ethics, 14(2), 149-167.

Adnanes, M. (2007). Social transitions and anomie among post-communist Bulgarian youth. Young, 15(1), 49-69 
Akbulut, Y., Sendag, S., Birinci, G., Kilicer, K., Sahin, M. C., \& Odabası, H. F. (2008). Exploring the types and reasons of Internet-triggered academic dishonesty among Turkish undergraduate students: Development of Internet-Triggered Academic Dishonesty Scale (ITADS). Computers \& Education, 51(1), 463-473.

Allen, J., Fuller, D., \& Luckett, M. (1998). Academic integrity: Behaviors, rates, and attitudes of business students toward cheating. Journal of Marketing Education, 20(1), 41-52.

Alleyne, P., \& Phillips, K. (2011). Exploring academic dishonesty among university students in Barbados: an extension to the theory of planned behaviour. Journal of Academic Ethics, 9(4), 323.

Bolin, A. U. (2004). Self-control, perceived opportunity, and attitudes as predictors of academic dishonesty. The Journal of Psychology, 138(2), 101-114.

Brown, B. S. (1995). The academic ethics of graduate business students: A survey. Journal of education for Business, 70(3), 151-157.

Brown, B. S. (1996). A comparison of the academic ethics of graduate business, education, and engineering students. College Student Journal, 30, 294-301.

Brown, B. S. (2000). The academic ethics of graduate business students: 1993 to 1998. Journal of Applied Business Research (JABR), 16(4), 105-112

Byrne, B. M. (1994). Structural equation modelling with EQS and EQS/windows: Basic concepts, applications, and programming. California: Sage Publishing.

Chapman, K. J., Davis, R., Toy, D., \& Wright, L. (2004). Academic integrity in the business school environment: I'll get by with a little help from my friends. Journal of Marketing Education, 26(3), 236-249.

Chukwuemeka, U., Gbenga, F., Sunday, N., \& Ndidiamaka, E. (2013). Academic dishonesty among Nigeria pharmacy students: A comparison with United Kingdom. African Journal Pharmacy and Pharmacology, 7(27), 1934-1941.

Cronbach, L. J. (1951). Coefficient Alpha and the Internal Structure of Tests. Psychometrika, 16, 297-334.

Dawkins, R. L. (2004). Attributes and statuses of college students associated with classroom cheating on a small sized campus. College Student Journal, 38(1), 116-129.

DeVellis, R. F. (2016). Scale development: Theory and applications (Vol. 26). Sage publications

Ellahi, A., Mushtaq, R., \& Bashir Khan, M. (2013). Multi campus investigation of academic dishonesty in higher education of Pakistan. International Journal of Educational Management, 27(6), 647-666.

Eminoglu, E., \& Nartgun, Z. (2009). A scale development study to measure academic dishonesty tendency of university students. Journal of Human Sciences, 6(1), 215-240. 
Ferrari, J. R. (2005). Impostor tendencies and academic dishonesty: Do they cheat their way to success? Social Behavior and Personality: an international journal, 33(1), 1118 .

Floyd, F. J. \& Widaman, K. F. (1995). Factor Analysis in the Development and Refinement of Clinical Assessment Instruments. Psychological Assessment, 7(3), 286299.

Fornell, C., \& Larcker, D. F. (1981). Evaluating structural equation models with unobservable variables and measurement error. Journal of marketing research, 39-50.

Gay, J. L., Evenson, K. R., \& Smith, J. (2010). Developing measures on the perceptions of the built environment for physical activity: a confirmatory analysis. International Journal of Behavioral Nutrition and Physical Activity, 7(1), 72.

George, D., \& Mallery, P. (2003). SPSS for Windows step by step: A simple guide and reference. 11.0 update (4th ed.). Boston: Allyn \& Bacon.

Gliem, J. A., \& Gliem, R. R. (2003). Calculating, interpreting, and reporting Cronbach's alpha reliability coefficient for Likert-type scales. In 2003 Midwest Research to Practice Conference in Adult, Continuing and Community Education. Columbus, $\mathrm{OH}$

Grimes, P. W., \& Rezek, J. P. (2005). The determinants of cheating by high school economics students: a comparative study of academic dishonesty in the transitional economies. International Review of Economics Education, 4(2), 23-45.

Hair, Jr, J. F., Black, W. C., Babin, B. J., \& Anderson, R. E. (2010). Multivariate data analysis (7th ed.). Upper Saddle River: Pearson Education International.

Harding, T. S., Carpenter, D. D., Finelli, C. J., \& Passow, H. J. (2004). Does academic dishonesty relate to unethical behavior in professional practice? An exploratory study. Science and engineering ethics, 10(2), 311-324.

Hayashi, K., Kamata, A. (2005). A note on the estimator of the alpha coefficient for standardized variables under normality. Psychometrika, 70(3), 579-586.

Hensley, L.C., Kirkpatrick, K.M. \& Burgoon, J.M. (2013). Relation of gender, course enrollment, and grades to distinct forms of academic dishonesty. Teaching in Higher Education, 18(8), 895-907.

Hooper, D., Coughlan, J. and Mullen, M. R. (2008). Structural Equation Modelling: Guidelines for Determining Model Fit. The Electronic Journal of Business Research Methods, 6(1), 53 - 60 .

Hu, L. T., \& Bentler, P. M. (1999). Cutoff criteria for fit indexes in covariance structure analysis: Conventional criteria versus new alternatives. Structural equation modeling: a multidisciplinary journal, 6(1), 1-55.

Iberahim, H., Hussein, N., Samat, N., Noordin, F., \& Daud, N. (2013). Academic dishonesty: why business students participate in these practices?. Procedia-Social and Behavioral Sciences, 90, 152-156. 
Imran, A. M., \& Nordin, M. S. (2013). Predicting the underlying factors of academic dishonesty among undergraduates in public universities: a path analysis approach. Journal of Academic Ethics, 11(2), 103-120.

Iyer, R., and Eastman, J. K. (2008). The Impact of Unethical Reasoning on Academic Dishonesty: Exploring the Moderating Effect of Social Desirability. Marketing Education Review, 18(2), 1-13.

Iyer, Rajesh, and J. K. Eastman: 2006, Academic Dishonesty: Are Business Students Different from other College Students?. Journal of Education for Business, 82(2), 101110 .

Joreskog, K. G., \& Sorbom, D. (1993). Lisrel 8: Structural equation modeling with the simplis command language. Lincolnwood: Scientific Software International, Inc.

Jurdi, R., Hage, H. S., \& Chow, H. P. (2011). Academic dishonesty in the Canadian classroom: Behaviours of a sample of university students. The Canadian Journal of Higher Education, 41(3), 1-35.

Kaur, K. (2011). A study of academic cheating among adolescents in relation to their personality, study involvement and socioeconomic status. PhD thesis submitted to MD University Rohtak, Haryana.

Keith-Spiegel, P., \& Whitley, B. (2001). Introduction to the special issue. Ethics \& Behavior, 11(3), 217-218.

Kidwell, L. A., Wozniak, K., \& Laurel, J. P. (2003). Student reports and faculty perceptions of academic dishonesty. Teaching Business Ethics, 7(3), 205-214.

Kline, R. B. (2005). Principles and practice of structural equation Modelling $\left(2^{\text {nd }}\right.$ ed.). New York: Guilford Publications, Inc.

Kothari, C. R., \& Garg, G. (2014). Research methodology methods and techniques (3 ${ }^{\text {rd }}$ edition). New Delhi: New Age International (P) Limited, Publishers.

Koul, L. (2009). Methodology of Educational Research (4 $4^{\text {th }}$ Edition. New Delhi: Vikas Publishing House.

Ledesma, R. G. (2011). Academic dishonesty among undergraduate students in a Korean university. Research in World Economy, 2(2), 25.

Likert, R. A. (1932). A Technique for the Measurement of Attitudes. Archives of Psychology, 22(140), 55.

Lim, V. K. G., \& See, S. K. B. (2001). Attitudes toward, and intentions to report, academic cheating among students in Singapore. Ethics \& Behavior, 11(3), 261-274.

Lima-Rodríguez, J. S., Lima-Serrano, M., \& Domínguez-Sánchez, I. (2015). Psychometric properties of an instrument to measure family disease management. International Journal of Clinical and Health Psychology, 15(3), 253-264. 
Mahne, K., \& Huxhold, O. (2014). Grandparenthood and subjective well-being: Moderating effects of educational level. Journals of Gerontology Series B: Psychological Sciences and Social Sciences, 70(5), 782-792.

McCabe, D. L., \& Trevino, L. K. (1993). Academic dishonesty: Honor codes and other contextual influences. The Journal of Higher Education, 64(5), 522-538.

McCabe, D. L., \& Trevino, L. K. (1997). Individual and contextual influences on academic dishonesty: A Multicampus Investigation. Research in Higher Education, 38(3), 379-396.

McCabe, D. L., Trevino, L. K., \& Butterfield, K. D. (2001). Dishonesty in academic environments: The influence of peer reporting requirements. The Journal of Higher Education, 72(1), 29-45.

Munoz-Garcia, A., \& Aviles-Herrera, M. J. (2014). Effects of academic dishonesty on dimensions of spiritual well-being and satisfaction: a comparative study of secondary school and university students. Assessment \& Evaluation in Higher Education, 39(3), 349-363.

Naghdipour, B., \& Emeagwali, O. L. (2013). Students' justifications for academic dishonesty: Call for action. Procedia-Social and Behavioral Sciences, 83, 261-265.

Nazir, M. S., \& Aslam, M. S. (2010). Academic dishonesty and perceptions of Pakistani students. International Journal of Educational Management, 24(7), 655-668.

Nelson, T., \& Shaefer, N. (1986). Cheating among college students estimated with the randomized-response technique. College Student Journal, 20(Fall), 321-325.

Netemeyer, R. G., Bearden, W. O., \& Sharma, S. (2003). Scaling procedures: Issues and applications. Sage Publications.

Nonis, S. \& Swift, C. O. (2010). An Examination of the Relationship between Academic Dishonesty and Workplace Dishonesty: A Multicampus Investigation, Journal of Education for Business, 77(2), 69-77.

Rawwas, M. Y., \& Isakson, H. R. (2000). Ethics of Tomorrow's Business Managers the Influence of Personal Beliefs and Values, Individual Characteristics, and Situational Factors. Journal of Education for Business, 75(6), 321-330.

Rawwas, M. Y., Al-Khatib, J. A., \& Vitell, S. J. (2004). Academic dishonesty: A crosscultural comparison of US and Chinese marketing students. Journal of Marketing Education, 26(1), 89-100.

Roig, M., \& DeTommaso, L. (1995). Are college cheating and plagiarism related to academic procrastination?. Psychological reports, 77(2), 691-698.

Saidin, N., \& Isa, N. (2013). Investigating Academic Dishonesty among Language Teacher Trainees: The Why and How of Cheating. Procedia-Social and Behavioral Sciences, 90, 522-529. 
Schreiber, J. B., Nora, A., Stage, F. K., Barlow, E. A., \& King, J. (2006). Reporting structural equation modeling and confirmatory factor analysis results: A review. The Journal of educational research, 99(6), 323-338.

Schumacker, R, E., \& Lomax, R. G. (2016). A beginner's guide to structural equation modeling $\left(4^{\text {th }}\right.$ Edition $)$. New York: Routledge.

Sims, R. L. (1993). The relationship between academic dishonesty and unethical business practices. Journal of Education for Business, 68(4), 207-211.

Singh, A. K. (2008). Tests, measurements and research methods in behavioural sciences $\left(5^{\text {th }}\right.$ ed.). Patna: Bharti Bhawan publishers and distributors.

Streiner, D. L. (1994). Figuring out factors: The use and misuse of factor analysis. Canadian Journal of Psychiatry, 39, 135-140.

Swift, C. O., \& Nonis, S. (1998). When no one is watching: cheating behaviors on projects and assignments. Marketing Education Review, 8, 27-36.

Tabachnick, B. G., \& Fidell, L. S. (2001). Using multivariate statistics (4th ed.). New York: Harper Collins Publishing.

Tabachnick, B.G. and Fidell, L.S. (1996). Using Multivariate Statistics 3rd ed. Harper Collins College, New York, NY.

Tadesse, T., \& Getachew, K. (2010). An exploration of undergraduate students' selfreported academic dishonesty at Addis Ababa and Jimma Universities. Ethiopian Journal of Education and Sciences, 5(2), 77-99.

Thomas, D. (2017). Factors that explain academic dishonesty among University Students in Thailand. Ethics \& Behavior, 27(2), 140-154.

Veneziano, L. \& Hooper, J. (1997). A method for quantifying content validity of healthrelated questionnaires. American Journal of Health Behavior, 21(1), 67-70.

Whitley, B. E., Jr. (1998). Factors associated with cheating among college students: A Review. Research in Higher Education, 39, 235-274.

Worthington, R. L., \& Whittaker, T. A. (2006). Scale development research: A content analysis and recommendations for best practices. The Counseling Psychologist, 34(6), 806-838.

Wymer, W., \& Alves, H. M. B. (2013). Scale development research in nonprofit management \& marketing: a content analysis and recommendation for best practices. International Review on Public and Nonprofit Marketing, 10(1), 65-86.

Yang, S. C., Huang, C. L., \& Chen, A. S. (2013). An investigation of college students' perceptions of academic dishonesty, reasons for dishonesty, achievement goals, and willingness to report dishonest behavior. Ethics \& Behavior, 23(6), 501-522. 